\title{
El Municipio de Sueca y su Ayuntamiento
}

En la zona Este de la provincia de Valencia, lindando al Norte con los términos de Valencia y Sollana, Sur con el de Cullera y el río Júcar, Este con el mar Mediterráneo y Oeste con los términos de Albalat de la Ribera y Sollana, se halla la ciudad de Sueca, principal centro arrocero de la Nación y espléndido exponente de la exuberante riqueza agrícola valenciana, cuyo ubérrimo término es fruto de las fatigas laborales de muchas generaciones de suecanos, que trocaron cañares, terrenos yermos e insanos en campos de pletórica producción.

Su población, según el censo de 1940, es de 20.109 habitantes de derecho y $\mathbf{1 9 . 8 9 0}$ de hecho.

\section{Antecedentes históricos}

Tiene su origen en los Fueros que en 7 de abril de 1261 promulgó el Rey Jaime I, creciendo y durando su importancia hasta que vencidos los árabes y con autoridad suficiente la monarquía para dominar la nobleza, comenzó a centralizar su acción el poder real, controlando las atribuciones del Municipio por mediación de sus representantes. Sueca era entonces Universidad o Municipio, que gobernaban:

El Lugarteniente General o Clavero, de la Orden de Montesa.

Los Oficiales de Justicia.

Los Oficiales Reales. 
E1 Justicia o el Alcalde ordinario era elegido anualmente por los Concells Generals el 22 de diciembre, conociendo en las causas civiles y criminales en primera instancia. En 8 de marzo de 1605 concedióse al Justicia y Jurados de Sueca la facultad de celebrar Consejo General en la parroquia. En 22 de diciembre de $\mathbf{1 6 6 5}$, este Consejo pasó a celebrarse en la Casa Consistorial de la villa.

Tal era la estructuración foral de Sueca en la Edad Media. La población era considerada también como Encomienda, Clavería, Lugartenencia de Montesa, Universidad y Villa, disfrutando asimismo del título de Corte: Cort del Ioch de Sueca, luego Ducado y actualmente Ciudad. Lo acreditan las actas municipales que comienzan en el año 1399.

\section{Título de Excelencia del Ayuntamiento}

Por Rel Decreto de 16 de mayo de 1899 ("Gaceta" del 19), queriénđose dar una muestra del Real aprecio a esta ciudad, por el creciente desarrollo de su población y por su importancia agrícola y comercial, se concedió a su Ayuntamiento el tratamiento de Excelencia.

\section{Su Escudo de Armas}

El Rvdo. P. Fr. Amado de C. Burguera Serrano, O. F. M., en su Historia Fundamental Documentada de Sueca y sus alrededores, publicada en el año 1924, nos ofrece el significado del Escudo de Armas diciendo:

"El Escudo de Armas de Sueca, por cuanto muestra a la higuera poblada, que en lenguaje heráldico significa candor y fecundidad, y atado a ella un mastín, que en el repetido lenguaje se traduce por fidelidad y vigilancia, denota que Sueca es una población eminentemete agrícola, sencilla y fecunda, vigilante y fiel, de caballerosidad altamente suyan.

No puede ser más acertada y elocuente esta sencilla expli- 
cación, que nos da una idea clara y concisa del significado heráldico de nuestro Escudo de Armas. Realmente, Sueca es sencillez, caballerosidad, hidalguía, honorabilidad, fidelidad, fecundidad, como lo pregona la idiosincrasia de su vecindario, que tiene alteza de miras, pundonor, corrección de costumbres, amor del hogar, honradez a carta cabal, desprendimiento, afabilidad en el trato, haciendo del trabajo un acto de servicio; y una serie de cualidades más, que sería prolijo enumerar, que le adornan y hacen que cuantos forasteros llegan aquí circunstancialmente, se quedan para siempre, orgullosos de residir en una ciudad tan acogedora.

\section{Estructura de la ciudad}

La población está integrada por el casco y los anejos.

El núcleo urbano está formado por un punto central, donde radica el Ayuntamiento y la plaza principal, desde el cual parten cuatro vías radiales que terminan en la carretera de circunvalación, hoy ya convertida en calle, y el resto de las calles vienen a enlazar estas cuatro vías principales. Tiene 4.620 edificios, estando destinados a vivienda 4.102. Los edificios en general son unifamiliares, siendo la construcción de los mismos a base de mampostería y fábrica de ladrillos, empleándose la madera en suelos y cubiertas, y estando dotados de alcantarillado y agua potabie.

Es insuficiente la edificación para la población existente, siendo causa inmediata de esta crisis la carestía del material de construcción y la cvidente especulación de solares. Este problema, que lo es de toda la Nación, ha inducido al Estado a resolver!o dictando acertadas medidas por medio de la Ley de Ordenación de Solares de 15 de mayo de 1945, que desarrolla una política eficiente contra la especulación de terrenos, al objeto de facilitar a las familias españolas un hogar y locales para el establecimiento de industrias, sacrificando para ello bastardos intereses de la propiedad particular que están en abierta oposición con los sagrados derechos de la sociedad en general. 
Los anejos del Municipio y su distancia al casco son los siguientes :

NOM B R E S

Barrio del Canal

Camino viejo de Cullera

Barrio de Granell

Barrio del Cardenal Cisneros

Barrio de Saca

Las Palmeras

Mareny de Barraquetes

Mareny de Vilches

Cerro de los Santos

Aldea del Perelló
Distancia

200 metros

300 "

$130 "$

$160 "$

$300 "$

$7.000 "$

$6.000 "$

$6.500 "$

$5.000 "$

10.000

\section{Extensión del Municipio en hectáreas}

E1 término municipal tiene una extensión de 8.409 hectáreas, repartidas del siguiente modo:

Zona urbana y de ensanche

\begin{tabular}{|c|c|c|}
\hline Ha. & a. & ca. \\
\hline 67 & 25 & 74 \\
\hline 7.267 & 95 & 53 \\
\hline 848 & 24 & 83 \\
\hline
\end{tabular}

Zona agrícola de regadío

Zona agrícola de secano

848

Parte forestal: Erial, cañar, árbo-

les de ribera e improductivo $\ldots . . \frac{225}{8.409} \frac{53}{00} \frac{90}{00}$

\section{A y untamiento}

En el año 1936 habían cuatro Tenencias de Alcaldía y el número total de Concejales era de veintidós. En 1941 el número de Tenientes Alcaldes era el mismo, y el de Gestores trece, hasta la fecha.

Como población superior a $\mathbf{2 0 . 0 0 0}$ habitantes, funciona en 
régimen de Comisión Permanente y Pleno, celebrando la primera sesión ordinaria semanalmente.

Está integrado por las Comisiones siguientes: Agricultura; Alumbrado, Agua y Bomberos; Asuntos Jurídicos; Asuntos Sociales y Casas Baratas; Caza y Pesca ; Cementerio; Estadística e Indeterminado; Fiestas; Gobernación y Personal; Hacienda; Instrucción Pública; Matadero y Mercados; Paseos y Arbolado; Policía Urbana y Obras; Propiedades y Derechos; Sanidad y Beneficencia.

Las funciones de la competencia de la Comisión Permanente se hallan distribuídas en la forma siguiente:

Alcaldía: Orden Público y Abastos.

Primera Tenencia de Alcaldía: Agricultura, Alumbrado, Agua y Bomberos, Fiestas, Hacienda, Matadero y Mercados, y Paseos y Arbolado.

Segunda Tenencia de Alcaldía: Caza y Pesca, Cementerio, Instrucción Pública, Policía Urbana y Obras, y Sanidad y Beneficencia.

Tercera Tenencia de Alcaldía: Asuntos Jurídicos, Asuntos Sociales y Casas Baratas, Estadística e Indeterminado, Gobernación y Personal, y Propiedades y Derechos.

\section{Organización de las oficinas}

Las oficinas del Excmo. Ayuntamiento están integradas por las dependencias de Secretaría, Intervención, Depositaría y Archivo.

La Secretaría se divide en los Negociados que se expresan, dotados del personal que se indica:

Negociado 1. - -Central: Oficial Mayor y un Auxiliar.

Negociado 2.0-Gobernación: Un Oficial y un Auxiliar.

Negociado $3 .^{\circ}-$ Fomento y Quintas: Un Oficial y un Auxiliar.

Negiciado $4 .^{\circ}-$ Hacienda: Dos Oficiales.

Negociado 5. -Delegación de Abastecimientos y Transpor- 
tes: Un Oficial de Estadística designado por la Delegación Provincial y dos Auxiliares.

Secretaría particular del Secretario; Un Auxiliar.

La Intervención comprende los Negociados siguientes:

Negociado 1. - Documentación y Presupuestos: Un Oficial.

Negociado 2. - Contabilidad: Un Oficial.

Negociado $3 .^{\circ}$-Arbitrios: Dos Oficiales, cinco Inspectores y un Jefe de los Servicios del Matadero.

Secretaría particular del Interventor: Un Auxiliar.

\section{Archivo y Biblioteca}

Tiene el Archivo documentos de gran valor histórico, tales como los Privilegios y otros documentos de los años 1401-1786; Actas desde 1399; Ordenes y Reglamentos 1668-1826, y otros muchos, que han sido objeto de consulta y estudio por destacados historiadores. La Biblioteca cuenta con más de 500 volúmenes, entre ellos varios diccionarios enciclopédicos, la colección de los clásicos y literatura moderna.

$$
V i g i l a n c i a
$$

El servicio de vigilancia municipal se halla a cargo de un Inspector, tres Cabos y veintiséis Guardias, en turnos de ocho horas.

\section{Guardería rural}

El servicio de guardería se halla confiado al Sindicato Local de Policía Rural, y lo prestan veintiséis Guardas Jurados, un Cabo y un Auxiliar, siendo este Sindicato una entidad modelo por su perfecta organización y recta administración.

También es de la competencia de este Sindicato la construcción de caminos y su reparación. 


\section{Servicios de incendios y saivamento}

Pocos Municipios en la provincia tienen organizado este servicio como este Ayuntamiento, a xcepción de la capital, contando con un Parque de Bomberos, instalado en un local propiedad del mismo. El personal se halla integrado por un Chófer y un Ayudante, un Comandante, un Ayudante de éste, tres Cabos y veinte Bomberos, organizado con su correspondiente Reglamento, que se considera como complemento a las reglas contenidas en las Ordenanzas Municipales.

El material está constituído por un auto-cuba Hispano-Suiza, diez picos, siete palas, tres azadones, un serrucho, cuatro capotes, treinta cascos, diez ganchos, un motor portátil con su bomba, cien metros de mangueras, una escalera portátil (de 18 metros, plegable), dos corrientes y catorce cubos.

$$
\text { Mercados }
$$

Las deficientísimas condiciones del mercado que existía en esta población dieron lugar a la tramitación del oportuno expediente para la construcción de uno nuevo, cuyas obras, que han dado principio, se adjudicaron mediante subasta por la suma de 2.502.469,28 pesetas, con la baja del 12,14 por 100 .

Este mercado estará formado por dos cuerpos de edificio unidos por un paso de cinco metros de ancho por seis de largo.

El cuerpo menor, de forma rectangular, destinado a pescadería, y el cuerpo mayor, de forma pentagonal, destinado a mercado propiamente dicho. Entre estos dos cuerpos y las alineaciones de las vías colindantes, queda un espacio de solar, en donde se instalan la vivienda del Conserje, la cámara frigorífica, el lavadero del pescado y los servicios de higiene. El conjunto mercado-pescadería tiene cinco puertas de acceso enlazadas por dos calles principales en forma de cruz y alrededor de las cuales van agrupados los puestos, formando calles secundarias en comunicación con las anteriores. Tendrá red de 
alcantarillado y de distribución de agua, e instalación eléctrica a base de 38 luces, sin perjuicio de la necesaria para los diferentes servicios. El número de puestos será de 216 en el mercado y 57 en la pescadería.

Para la construcción de este mercado, además del solar correspondiente al antiguo, ha sido necesario expropiar 19 edificios.

Tiene la población otro mercado en el poblado del Perelló, de reciente construcción.

$$
\text { Matadero }
$$

Se halla instalado en un edificio construído de muros y manpostería mixta, pilares de ladrillos, cubiertas de cuchillos de madera y tejas planas; dotado de los servicios de agua y luz; con corrales, salas de sacrificio, patios, despacho dè inspección, etc.

El personal a su servicio es un Jefe, un Conserje y una limpiadora.

$$
\text { Cementerios }
$$

Existen dos cementerios: el general y el civil.

El general, con 2.425 nichos y 1.488 sepulturas en tierra, además de los panteones de propiedad particular, y el civil, con 20 nichos y 40 sepulturás en tierra.

Tiene su Capilla, Salas de observación y autopsias.

\section{Personal sanitario}

Está formado por cuatro Médicos de Asistencia Pública Domiciliaria, un Tocólogo municipal, tres Farmacéuticos, cuatro Practicantes, dos Matronas y tres sanitarios. 


\section{Inspección veterinaria}

Prestan el servicio tres Inspectores Municipales Veterinarios que verifican la inspección de sustancias alimenticias en mercado y matadero, reconocimiento e inspección macro y microscópica de las reses porcinas y el sacrificio domiciliario, estadística de sanidad veterinaria, vacunación antirrábica obligatoria, reconocimiento sanitario del ganado explotado en régimen de pastoreo y sanatorio zootécnico de los sementales equinos, vacunos y porcinos, de paradas particulares y de la parada oficial y el servicio de asesoramiento técnico de la Junta Local Agropecuarià y de la Delegación de Abastecimientos.

\section{Hospitales}

Existe un Hospital, de cuya administración y funcionamiento está encargada la llamada “Junta del Santo Hospital de Caridad", cuyos miembros son los que componen la Comisión Mi. nicipal de Beneficencia y otros vitalicios, de la que es presidente el Alcalde. Posee ingresos propios procedentes de sus bienes y de los donativos que recibe, siendo su capacidad de cuarenta plazas.

Se halla instalado en un edificio municipal y está dotado de amplias salas y quirófano, prestando servicio facultativo los Médicos de Asistencia Pública Domiciliaria y Practicantes, asistidos de las Hermanas de la Congregación de San Vicente de Paul.

\section{Centro Maternal de Urgencia}

Funciona un Centro Maternal de Urgencia, que es uno de los mejores de España, con magníficas salas, espléndidas instalaciones, calefacción y baños, y material modernísimo, que lo hacen acogedor en extremo. Creado por el Estado, merced a la iniciativa del Tocólogo municipal y del Ayuntamiento, con 
la ayuda económica también del señor Ingeniero Jefe de la Estación Arrocera de esta ciudad, se halla bajo la dirección del Maternólogo del Estado, y su finalidad principal es la asistencia de los partos anormales (distócicos) que ocurran en Sueca, Cullera, Sollana, Albalat de la Ribera, Poliñá del Júcar, Riola, Fortaleny, Llaurí y Favareta, con un censo de población aproximada de 45.000 habitantes, comprendiendo la asistencia a la beneficencia municipal y distocias sociales.

El Instituto Nacional de Previsión tiene dos salas reservadas para los beneficiarios del Seguro de Maternidad.

También existe en el Centro un Dispensario de Maternología y Puericultura, que presta sus servicios a un millar de embarazadas y a más de dos mil niños, anualmente.

\section{Otros Dispensarios}

Existen en la ciudad Dispensarios antivenéreo y antitracomatoso, regentados por especialistas designados por el Estado.

$$
\text { Escuelas }
$$

La Corporación Municipal, atenta en todo tiempo al problema de la enseñanza, y como consecuencia de su comprensión de que la labor educativa a desarrollar en la escuela es la mejor ofrenda al interés común de la Patria, ha fomentado la instrucción escolar con el fin de formar una juventud que tenga las virtudes de nuestra raza, en el logro de la unidad de destino de la Patria. Razón por la cual en esta ciudad se ha enfocado siempre bien la solución del problema de la enseñanza, no faltando ilustres filántropos como don Emilio Carrasquer García, que legó sus bienes para la construcción del Grupo Escolar que lleva su nombre y una casa para la instalación de una Biblioteca.

El servicio de Instrucción primaria se halla perfectamente instalado en dos espléndidos Grupos Escolares de seis grados cada uno (de ambos sexos), "Carrasquer" y "Cervantes", que 
son modelo en la provincia por reunir todos los requisitos que requiere la más exigente técnica, existiendo además dos unitarias de niños, dos de niñas, dos de párvulos, un grupo escolar en el Perelló de cuatro grados, un Colegio de Enseñanza Media, una Escuela de niños y otra de niñas en el poblado del Mareny de Barraquetes; treinta y dos Maestros nacionales, dos privados, dos Maestros municipales y quince Profesores.

Existe una Escuela Municipal de Artes y Oficios, con un Profesor y dos Auxiliares, para la preparación de la Artesanía iocal.

El Ayuntamiento no sólo se preocupa de las Escuelas sino también de facilitar a los Maestros casa-habitación alegre, higiénica y confortable, habiendo comenzado las obras de construcción de un grupo de ocho viviendas, que se adjudicaron por subasta por la suma de $369.363,09$ pesetas, habiéndose concedido por el Ministerio de Educación Nacional la subvención de 24.000 pesetas solicitada, que ha de percibirse en los dos plazos señalados en el artículo 16 del Decreto de 15 de junio de 1934.

\section{Vias públicas}

Está dotada la ciudad de una pavimentación blindada de adoquines, losetas y mosaico, en buen estado, cuya mejora se va extendiendo a las vías públicas situadas en el extrarradio, preseñtando un aspecto de urbanización que no lo tienen muchas capitales.

\section{Monte.s}

Tiene el Municipio un pequeño monte denominado "Cerro de los Santos o $\mathrm{Na}$ Molins", emplazado en el centro de la extensa zona arrocera, desde cuyo punto se admira el bello paisaje que forman ora los campos invadidos de agua en la época de las tiradas de aves acuáticas, que forman un inmenso espejo policromado por el colorido de las plumas de las aves; ora el tapiz de oro formado por las espigas del arroz en madurez. 
Espléndido lugar para instalar un Parador para el Turismo, por ser un balcón permanente magníficamente abierto al mar, a la Albufera y a la hermosa vega valenciana.

En el Cerro hay una capilla dedicada a los Santos de la Piedra, Abdón y Senén.

$$
\text { Pósitos }
$$

El Pósito de Sueca ha tenido siempre una actuación brillante, llegando a disponer de un capital de 91.228 pesetas, en junio de 1936. Hoy, después de aplicar a dicho capital la Ley de Desbloqueo, ha quedado reducido a 24.547 pesetas, y debido al nuevo sistema de préstamo agrícola, por mediación de los Sindicatos Arroceros, su desenvolvimiento es débil, teniendo repartido en préstamos 22.125 pesetas. Se rige por el Reglamento de 25 de agosto de 1928.

\section{Bienes del Municipio}

Constituyen el patrimonio municipal los bienes siguientes:

\begin{tabular}{lrrr} 
& \multicolumn{1}{c}{ Valor } & Renta \\
\cline { 2 - 2 } Fincas urbanas ............... & $\mathbf{2 . 0 2 3 . 0 5 0}$ & 2.250 \\
Fincas rústicas (propios) .... & $\mathbf{9 2 . 1 9 0}$ & $\mathbf{1 5 0}$ \\
Fincas rústicas (comunales). & $\mathbf{3 0 0 . 0 0 0}$ & \\
Valores mobiliarios : & & \\
Una lámina Deuda Perpetua & & \\
4 por 100 valor nominal.... & $\mathbf{1 6 . 0 6 5 , 1 3}$ &
\end{tabular}

$$
\text { Presupuestos }
$$

Pesetas

Importa el presupuesto ordinario actual. $1.978 .683,00$ Importa el presupuesto extraordinario en ejecución $3.829 .415,97$

Presupuesto carcelario del Partido $42.818,00$ Presupuesto carcelario Municipal $18.350,00$ 


\section{Riqueza del Municipio}

\begin{tabular}{|c|c|}
\hline & Pesetas \\
\hline mporta la riqueza imponible de urbana. & $1.966 .206,07$ \\
\hline Importa la riqueza imponible de rústica. & $5.771 .837,75$ \\
\hline $\begin{array}{c}\text { Importa Cuotas Tesoro Contribución in- } \\
\text { dustrial }\end{array}$ & $316.531,42$ \\
\hline $\begin{array}{c}\text { Importa Cuotas Tesoro Automóviles in- } \\
\text { dustrial }\end{array}$ & $30.348,00$ \\
\hline $\begin{array}{c}\text { Importa Cuotas Tesoro Usos y Consu- } \\
\text { mos, Turismo y Motos } \ldots \ldots \ldots \ldots \ldots \ldots \ldots\end{array}$ & $6.432,00$ \\
\hline
\end{tabular}

\section{Riqueza agricola}

No era exagerada la afirmación que haciamos al principio de la importancia agrícola de esta ciudad, si tenemos en cuenta que la estadística de la producción arrocera en el último quinquenio es la siguiente:

$\begin{array}{llll}1942 & \ldots \ldots \ldots \ldots \ldots \ldots \ldots \ldots \ldots . & 21.664 .303 \text { kgs. } \\ 1943 & \ldots \ldots \ldots \ldots \ldots \ldots \ldots \ldots \ldots . & 22.510 .191 & " \\ 1944 & \ldots \ldots \ldots \ldots \ldots \ldots \ldots \ldots \ldots \ldots . & 26.323 .413 & " \\ 1945 & \ldots \ldots \ldots \ldots \ldots \ldots \ldots \ldots \ldots \ldots . & 22.435 .114 & \\ 1946 & \ldots \ldots \ldots \ldots \ldots \ldots \ldots \ldots \ldots \ldots \ldots & 16.642 .415\end{array}$

$\mathrm{Y}$ eso en un período en que, a consecuencia de la escasez de abonos, las tierras se hallan depauperadas, pues la cosecha en época normal ha sido de un promedio de 33.000 .000 de kilogramos.

\section{Sindicato Arrocero}

De la recogida de la cosecha del arroz está encargado el Sindicato Arrocero, dependiente de la Federación Sindical de Agricultores Arroceros y encuadrado en el Sindicato Nacional del Arroz. 
Realiza una gran labor social facilitando préstamos dinerarios, a módico interés, a los agricultores, con la garantía de la cosecha, y reparte entre ellos los cupos de abonos que se le asignen, piensos y racionamiento de aceite, pan y arroz parz los trabajadores y cupo de arroz a los cosecheros.

\section{Estación Arrocera}

Dependiente del Instituto Nacional de Investigaciones Agronómicas del Ministerio de Agricultura, hay establecida en la población una Estación Arrocera, cuya distribución de trabajos y servicios que presta es:

Cerealicultura y otros cultivos de regadío: experiencias de trigo, cebada, maíz, textiles, cultivos varios y arroz.

Operaciones complementarias del cultivo: trilla, secado, almacenamiento, elaboración y aplicaciones.

Cultivo y maquinaria: labores y riegos, abonos, experiencia y demostración, máquinas y motores.

Mejora de variedades: Citología-Genética, Biología-Biometria, Selección-Demostración-Experimentación, Aclimatación e Hibridación.

Agrología y climatología: Datos climatológicos, gráficos de fitoclima, Física del suelo, Química del suelo y Mapas Edológicos.

Plagas: Estudios propios, experimentación, demostración y medios de destrucción.

Estudios económico-sociales: Estadísticas, costes de producción, problema arrocero, distribución y costes de elaboración.

Servicios generales: Consultas generales, informes, asesoramientos, proyectos y presupuestos, administración, contabilidad, distribución de semillas, material, elaboración y trilladora, secadora y molino, laboratorios, dctámenes de muestras, análisis de abonos, etc. 


\section{Riegos}

Una perfecta y extensa red de canales y acequias, de origen árabe, que toman el agua del río Júcar, facilita el riego de todo el término, cuya ordenación está confiada al llamado Sindicato de Riegos; entidad que tiene participación en el pantano de Alarcón y se halla bajo la jurisdicción de la Confederación $\mathrm{Hi}$ drográfica del Júcar.

Gobierna el Sindicato una junta integrada por competentes y honrados labradores, que lleva una pulquérrima administración y atiende de modo ejemplar el reparto del agua, siguiendo un sistema práctico y eficiente.

El Municipio tiene representación en la Junta de Desagüe del lago de la Albufera por medio de labradores, propietarios de campos en su frontera.

\section{Factor social}

La población obrera de la ciudad podemos clasificarla en la forma siguiente: $\mathbf{3 . 6 7 4}$ obreros agrícolas, $\mathbf{5 5}$ de la industria ganadera, 275 de construcción, 140 de la madera, 270 de la alimentación, 45 de metalurgia, 94 de transportes, 620 de comercio en general y 790 de otras industrias y profesiones.

\section{Asistencia social}

Además del servicio gratuito médico-farmacéutico de la beneficencia municipal y del Seguro de Enfermedad que satisface el Ayuntamiento a los fucionarios municipales, existen en la población dos instituciones ejemplares, como son el Asilo de Ancianos Desamparados y el de la Encarnación. En aquél encuentran amparo y cobijo los ancianos pobres, y en el segundo los huérfanos indigentes. El primero instalado en un amplio y hermoso edificio formado por varios cuerpos de obra, digno de admiración, y el segundo tiene un establecimiento más modes- 
to, hallándose servidos por las Congregaciones de Hermanitas de Ancianos Desamparados y de San Vicente de Paul, respectivamente, y sostenidos ambos, en su mayor parte, por la caridad pública del vecindario.

\section{$J u s t i c i a$}

Sueca es cabeza de Partido judicial y comprende los pueblos de Cullera, Tabernes de Valldigna, Sollana, Almusafes y Albalat de la Ribera, y el Juzgado municipal extiende su jurisdicción comarcal: a los Municipios de Sollana, Almusafes y Albalat de la Ribera.

\section{Parques y Jardines}

E1 viajero que llega a Sueca en el tren queda extasiado ante el bello jardín que admira a sus pies.

Una cerca de ladrillo rematada por motivos ornamentales, esbeltas columnas, losetas policromadas, y en los macetones colocados en lo alto, esparragueras y cactus.

Macizos en zonas verdes con sus bordillos recortados.

Macizos en rosaleda, llenos de flores, muchas flores, pétalos sedosos y aterciopelados.

Jacintos, alelíes, mimosas, claveles, camelias, orquídeas ; esencias embriagadoras, perfumes, jardín de ensueño: es el Parque Ruiz de Alda, con sus arbustos, acacias, palmeras, longevos plátanos de sombra; espacioso paseo con sus aceras y sus farolas; estilo renacimiento valenciano.

\section{Pl $a$ y $a s$}

Sueca tiene toda su zona Este, entre los términos de Valencia y Cullera, bañada por el mar. .

Extensa zona playera de unos ocho kilómetros de longitud, que comprende los poblados del Perelló, Palmeras, Mareny de 
Barraquetes y Mareny de Vilches, con sus correspondientes casitas y chalets de recreo, y junto a esta playa hermosísima y limpia, huertos de naranjos, flor de azahar.

El veraneante puede alternar sus horas de solaz esparcimiento junto al mar con el deporte de la pesca, en los canales de la Albufera y golas del Perelló y Mareny; con los paseos en barca $y . .$. en el silencio de la noche en vigilia, el sedante de la rondalla de guitarras y bandurrias y la melancólica belleza de alguna canción.

\section{Tiradas de aves acuáticas}

Fijado por la IV Federación Regional de Caza el Calendario deportivo, la Junta de Tiradas, presidida por el Alcalde e integrada por varios Gestores Municipales y representaciones del Santo Hospital de Caridad, Sindicatos de Riegos y Policía Rural, y técnicos de la Asociación de Caza y Pesca, se anuncia la celebración de la subasta de las replazas, que tiene lugar en la segunda quincena de octubre.

El Coto de Tiradas, que está formado por una inmensa zona de campos de arroz, que para esta finalidad ceden los propietarios, está integrado por un promedio de sesenta y cinco replazas, siendo el importe de adjudicación de las mismas en el último año de 368.150 pesetas; tiradas que tienen fama mundial y en la que se cazan las variedades de fúlicas, ánades, rabilargo, culón, sarseta y otras, constituyendo la primera de ellas un día de fiesta local por la extremada animación de forasteros y la afluencia de la mayor parte de los suecanos a los cotos y aledaños.

Revela la importancia del deporte, que en el año citado el puesto número uno fué rematado en la cantidad de 37.000 pesetas.

El producto de la recaudación de los puestos, previa deducción de una pequeña participación al Ayuntamiento y el gasto que se ocasiona para el sostenimiento de un cuerpo de cuarenta guardas, aproximadamente, reparaciones en los campos, etcétera, se reparte entre los Sindicatos de Riegos y Policía Rural y Santo Hospital de Caridad. 


\section{Feria y Fiestas}

La vida en Sueca está impregnada del espíritu cristiano y por ende es muy grande su fervor religioso. Tiene dedicadas sus fiestas:

El 17 de enero a San Antonio Abad, con su clásico "porrat", bendición y desfile de caballerías.

El 30 de julio a los Santos de la piedra San Abdón y San Senén, que son trasladados a la población desde el Cerro de los Santos, y luego procesionalmente a la iglesia parroquial de San Pedro Apóstol.

Primer domingo de septiembre, fiesta del Santísimo Cristo.

8 de.septiembre: fiesta principal dedicada a Nuestra Excelsa Patrona la Virgen de Sales; gran feria, campanas al vuelo, "tabalet", dulzaina, bandas de música, cohetes, fuegos de artificio; trajes de fiesta, joyas, esplendor, entusiasmo, gran religiosidad, fervorosa adoración; sentidas plegarias a la Virgen, y Ella, escoltada y conducida por soldados de Sueca, recorre las calles en solemne procesión, recibiendo los suecanos su amor, su bondad y su gracia, y genuflexos elevan sus oraciones.

Tales son, en sintesis, las características del Municipio de Sueca y su Ayuntamiento, faltándonos, y con ello terminamos, hacer una referencia de las personalidades suecanas que dieron gloria a la ciudad, mereciendo destacar por su acusado relieve a Guillermo Tovía y Pedro Viñoles, en Agricultura; N. Frígola y Juan Bta. Ferrer Cardona, en las Armas; Juan Garí y Bernardo Esteve, en la Justicia ; Francisco Baldoví Corberá, José Bernat y Baldoví y José Serrano Marí, en las Letras, como así lo pregonan los cuatro carteles que figuran en los ángulos del artesonado del Salón de Sesiones del Ayuntamiento, a cuyos nombres hay que añadir Simón Vila Vendrell, que sobresalió en las Ciencias Químicas, y gran filántropo, que legó sus bienes al Santo Hospital de Caridad; al también filántropo, ante- 
riormente citado, Emilio Carrasquer García, y al artífice de la melodía y músico genial José Serrano Simeón. Y en el orden espiritual a Andrés Sales, que el 14 de febrero de 1361, labrando la tierra, halló una piedra con la imagen de la Virgen, que fué proclamada Patrona de la ciudad con el nombre de Virgen de Sales el 12 de agosto de 1902, colocándose la primera piedra de su templo el 1 de mayo de 1753.

\section{Antonio Ramón y Pastor \\ Secretario del Ayuntamiento de Sueca.}

